\title{
Biologia floral e polinização deArrabidaea conjugata (Vell.) Mart. (Bignoniaceae) $^{1}$
}

\author{
Maria Célia Rodrigues Correia ${ }^{2,3}$, Maria Célia B. Pinheiro ${ }^{2}$ e Heloísa Alves de Lima
}

Recebido em 09/05/2003. Aceito em 07/12/2004

\begin{abstract}
RESUMO - (Biologia floral e polinização de Arrabidaea conjugata (Vell.) Mart. (Bignoniaceae)). O trabalho aborda a biologia floral, a atividade forrageira dos visitantes florais (polinizadores e pilhadores), os eventos fenológicos e o sistema de reprodução de Arrabidaea conjugata (Vell.) Mart. (Bignoniaceae), em área de vegetação de restinga, município de Maricá, Rio de Janeiro, no período 1997 a 2000. A espécie estudada tem flores com antese diurna, lilases, tubulosas, hermafroditas, odoríferas e oferecem néctar como recurso floral. O néctar é secretado por um disco localizado na base do gineceu e é acumulado em câmara nectarífera. Os grãos de pólen são liberados gradativamente, prolongando-se a fase de doação de pólen. As abelhas Euglossa cordata Linnaeus, Centris analis Fabricius e C. tarsata Smith são os polinizadores da espécie. Destaca-se pilhagem primária de néctar, por abelhas, e secundária, por borboletas e beija-flor. A espécie é auto-incompatível, apresentando baixos índices de formação de frutos em condições naturais (Frutos/Flores = 12,2\%). Foi registrado padrão de floração "cornucópia”, entre os meses de dezembro a março (estação quente/chuvosa), com pico em janeiro. As sementes são anemocóricas e liberadas gradativamente na estação fria e seca.
\end{abstract}

Palavras-chave: restinga, biologia floral, pilhadores de néctar, sistema de reprodução, fenologia, melitofilia

ABSTRACT - (Floral and pollination biology of Arrabidaea conjugata (Vell.) Mart. (Bignoniaceae)). This work deals with the floral biology, the foraging activities of floral visitors (pollinators and robbers), phenology and reproductive system of Arrabidaea conjugata (Vell.) Mart. (Bignoniaceae) in the "restinga" of Maricá, Rio de Janeiro, Brazil, from 1997 to 2000. The flowers display daytime anthesis and last only one day. These attractive pink flowers are tubular, hermaphroditic, odoriferous and produce nectar as the floral reward. The nectar is secreted by a nectariferous disk concealed within a chamber. The pollen grains are gradually released throughout anthesis, extending the pollen presentation phase. The bees Euglossa cordata Linnaeus, Centris analis Fabricius and C. tarsata Smith are the pollinator species. Primary and secondary nectar pilferage by several bees, butterflies and a hummingbird is found in A. conjugata. The species is selfincompatible and has low fruit set (Fruit/Flower $=12.2 \%$ ). Flowering of A. conjugata lasts from December to March (hot, rainy season) with a peak in January. The seeds are anemocoric and dispersal peaks in the cold, dry season.

Key words: "restinga", floral biology, nectar robbers, reproductive system, phenology, melitophyly

\section{Introdução}

A família Bignoniaceae é composta por cerca de 120 gêneros e 800 espécies predominantemente neotropicais, com poucas espécies distribuídas nas regiões temperadas (Gentry 1979a;1979b). Nas florestas tropicais mais de 600 espécies são lianas, aspecto ecológico que faz de Bignoniaceae a mais importante das famílias de lianas da América tropical (Gentry 1990). Representantes desta família são particularmente freqüentes no norte da América do Sul, com poucos gêneros ocorrendo na África, Madagascar e Ásia; somente dois gêneros ocorrem simultaneamente no Novo e Velho Mundo - Campsis e Catalpa (Schneider \& Londero 1965).

Estudos abrangentes sobre a biologia reprodutiva de Bignoniaceae estão principalmente representados pelos trabalhos pioneiros de Gentry (1974a; 1974b; 1976), que mostrou que os diferentes padrões da morfologia floral das Bignoniaceae estão vinculados a cinco grupos de vetores de pólen (morcegos, beijaflores, mariposas, borboletas, abelhas de pequeno, médio e grande porte). $\mathrm{O}$ referido autor, em seus estudos sobre padrões fenológicos de floração, observou e descreveu cinco padrões distintos para as Bignoniaceae da América Central (posteriormente

\footnotetext{
1 Parte do projeto "Estudo da biologia floral, fenologia e sistema de reprodução das espécies de Bignoniaceae existentes no $1^{\circ}$ e $2^{\circ}$ cordões arenosos nas restingas de Maricá e Itaipuaçu/RJ". SID n. 3701041004-6

2 Universidade Federal do Rio de Janeiro, Laboratório de Biologia Reprodutiva, Departamento de Botânica, Museu Nacional, Quinta da Boa Vista s/n, CEP 20940-040, São Cristóvão, RJ, Brasil

3 Autor para correspondência: mcorreia@acd.ufrj.br
} 
utilizados por diversos autores, para outros grupos vegetais), concluindo que a alta diversidade dessas espécies parece estar relacionada aos diferentes padrões fenológicos apresentados. Paralelamente aos trabalhos de Gentry, destacam-se, ainda, estudos de biologia da reprodução (Vieira et al. 1992; GobattoRodrigues \& Stort 1992), estudos sobre o sistema de auto-incompatibilidade (Gibbs \& Bianchi 1993; 1999; Bittencourt Jr. et al. 2003), estudos sobre nectários extraflorais (Elias \& Gelband 1975; 1976; Elias \& Prance 1978; Elias 1983) e estudos sobre polinização (Barrows 1977; Whitham 1977; Stephenson \& Thomas 1977; Bertin 1982; Barros 2001).

Bignoniaceae está incluída entre as 15 famílias melhor representadas nas restingas do Estado do Rio de Janeiro (Araújo \& Henriques 1984), com registro de 12 gêneros e 19 espécies (Pereira \& Araújo 2000).

O presente trabalho objetiva fornecer informações sobre a biologia floral, estudando os processos biológicos ligados ao período de vida da flor, destacando a área estigmática e nectário floral, a ecologia da polinização, com ênfase nas atividades forrageiras dos polinizadores efetivos e dos pilhadores de néctar, o sistema reprodutivo e a fenologia reprodutiva de Arrabidaea conjugata, espécie presente nas restingas fluminenses.

\section{Material e métodos}

As observações de campo foram realizadas em populações de Arrabidaea conjugata (Vell.) Mart. na restinga de Maricá, RJ, durante o período de janeiro/1997 a dezembro/2000. Não sendo possível delimitar com clareza cada indivíduo, em função do hábito trepador, foram escolhidas cinco áreas, distantes no mínimo $30 \mathrm{~m}$ e no máximo $1.000 \mathrm{~m}$, para conduzir as observações fenológicas e os experimentos de polinização. Durante o período de estudo foram registrados dados sobre as fenofases de floração, frutificação, crescimento vegetativo e dispersão das sementes. A classificação do padrão de floração seguiu proposta de Gentry (1974a). A pesquisa de campo incluiu, registros sobre morfologia e eventos florais (horário de abertura, duração da antese, modificações sofridas ao longo da antese) e comportamento dos visitantes ao longo do dia. A diferenciação entre polinizadores e pilhadores baseouse no comportamento de forrageio apresentado pelos visitantes durante a coleta do recurso floral. A classificação relativa aos pilhadores de néctar está de acordo com Inouye (1983). O vôo forrageiro dos visitantes (chegada e saída da área de estudo) foi observado, anotando-se o número de flores visitadas por planta. A freqüência dos visitantes florais foi registrada em todas as áreas selecionadas para estudo, a partir de 80 horas de observação.

Para o estudo do sistema de reprodução foram aplicados experimentos de polinização, sempre realizados pela manhã e usando-se plantas das cinco áreas de estudo. 1) Autopolinização manual - botões em pré-antese foram ensacados e, no dia seguinte, as flores foram manualmente polinizadas com seu próprio pólen; 2) Polinização cruzada (xenogamia) - botões em pré-antese foram emasculados e ensacados. No dia seguinte, as flores foram polinizadas manualmente com pólen de flores ( 1 a 4 ) de outra área. 3) Polinização em condições naturais (controle) - flores não submetidas a tratamento e não ensacadas foram marcadas e acompanhadas até a senescência ou a maturação do fruto.

Os estigmas de flores frescas foram examinados sob microscópio estereoscópio e óptico para análise e classificação da área estigmática (Heslop-Harrison \& Shivanna 1977). A presença de substâncias lipídicas e a identificação de grãos de amido nos grãos de pólen foi, respectivamente, detectada com Sudan III e IV e Lugol (Johansen 1940). A viabilidade dos grãos de pólen foi estimada usando-se carmim acético a $1 \%$ (Alexander 1980). O material botânico coletado encontra-se depositado no Herbário do Museu Nacional (R198561, R198564 e R198565).

\section{Resultados}

Arrabidaea conjugata é uma liana herbácea que ocorre nas restingas do Rio de Janeiro, destacando-se por ser muito ramificada, com ramos longos e escandentes, os quais recobrem totalmente as plantas vizinhas. Suas flores são lilases, zigomorfas, tubulosas, hermafroditas, odoríferas e nectaríferas (Fig. 1). As flores reúnem-se em inflorescências terminais tirsóides, com cerca de $90 \mathrm{~cm}$ compr. (Fig. 2), sempre destacadas da folhagem e emitidas sincronicamente nas diversas populações estudadas.

O cálice é tubular, gamossépalo, lilás com média de $0,78 \mathrm{~cm}$ compr. $(\mathrm{N}=50$; desvio padrão $=0,10)$ e revestido por pequenos tricomas brancos. Nectários extraflorais ocorrem na superfície externa das sépalas, em número de 1 a 6 por cálice, dispostos aleatoriamente ( $\mathrm{N}=106$ flores). A atividade destes nectários inicia-se em torno de 72 horas antes da abertura floral e termina no início da antese. Estes nectários são muito visitados 
pelas formigas Camponotus crassus Mayr, Ectatomma quadridrens Fabricius e Pseudomyrmex sp.

A corola tem forma campanulada, achatada dorsoventralmente, com cinco lacínios livres, média de $3,29 \mathrm{~cm}$ compr. $(\mathrm{N}=50$; desvio padrão $=0,34)$ e cor lilás, a qual é acentuada pelo revestimento de tricomas também lilases. Internamente, a corola apresenta um guia de néctar branco e glabro; fora dessa região ocorrem pequenos tricomas brancos, distribuídos esparsamente. $\mathrm{O}$ androceu apresenta quatro estames didínamos, insertos, epipétalos e um estaminódio reduzido (Fig. 3). Os filetes são brancos e as anteras lilases, ditecas e com deiscência rimosa. Após a deiscência, os bordos das tecas permanecem unidos, não ocorrendo exposição de grãos de pólen. A liberação dos grãos de pólen dá-se exclusivamente por meio da pressão exercida pelos polinizadores sobre as anteras, durante suas visitas. Assim, a cada visita, grumos de grãos de pólen vão sendo liberados. O grão de pólen é branco, com exina não esculturada, diâmetro polar médio de $34,18 \mu \mathrm{m}(25-50 \mu \mathrm{m}, \mathrm{N}=50)$, apresentando "pollenkitt" e 83,57\% de viabilidade ( $\mathrm{N}=775$ grãos) de 50 flores nas cinco áreas. Grãos de amido estão presentes somente nos grãos de pólen dos botões em pré-antese, sendo hidrolisados no período que antecede a abertura floral.

O gineceu é constituído por um ovário súpero, oblongo, lilás, com média de 38 óvulos ( $\mathrm{N}=20$ flores; desvio padrão $=6,84$; Fig. 4). O estilete é branco e varia de 1,7-2,0 cm compr., de modo que a área estigmática pode atingir o nível das anteras mais baixas, ou o nível das mais altas. O estigma é bífido, sensitivo e do tipo úmido e papiloso, com papilas que se diferenciam pelo tamanho, sendo umas longas e outras curtas.

O nectário floral é em forma de disco e localizase na base do gineceu (Fig. 5). O néctar começa a ser secretado na fase de botão em pré-antese e é produzido continuamente por toda a vida da flor. O néctar floral é acumulado numa câmara nectarífera protegida pela concentração de tricomas simples e capitados que se dispõem fechando a base do tubo da corola.
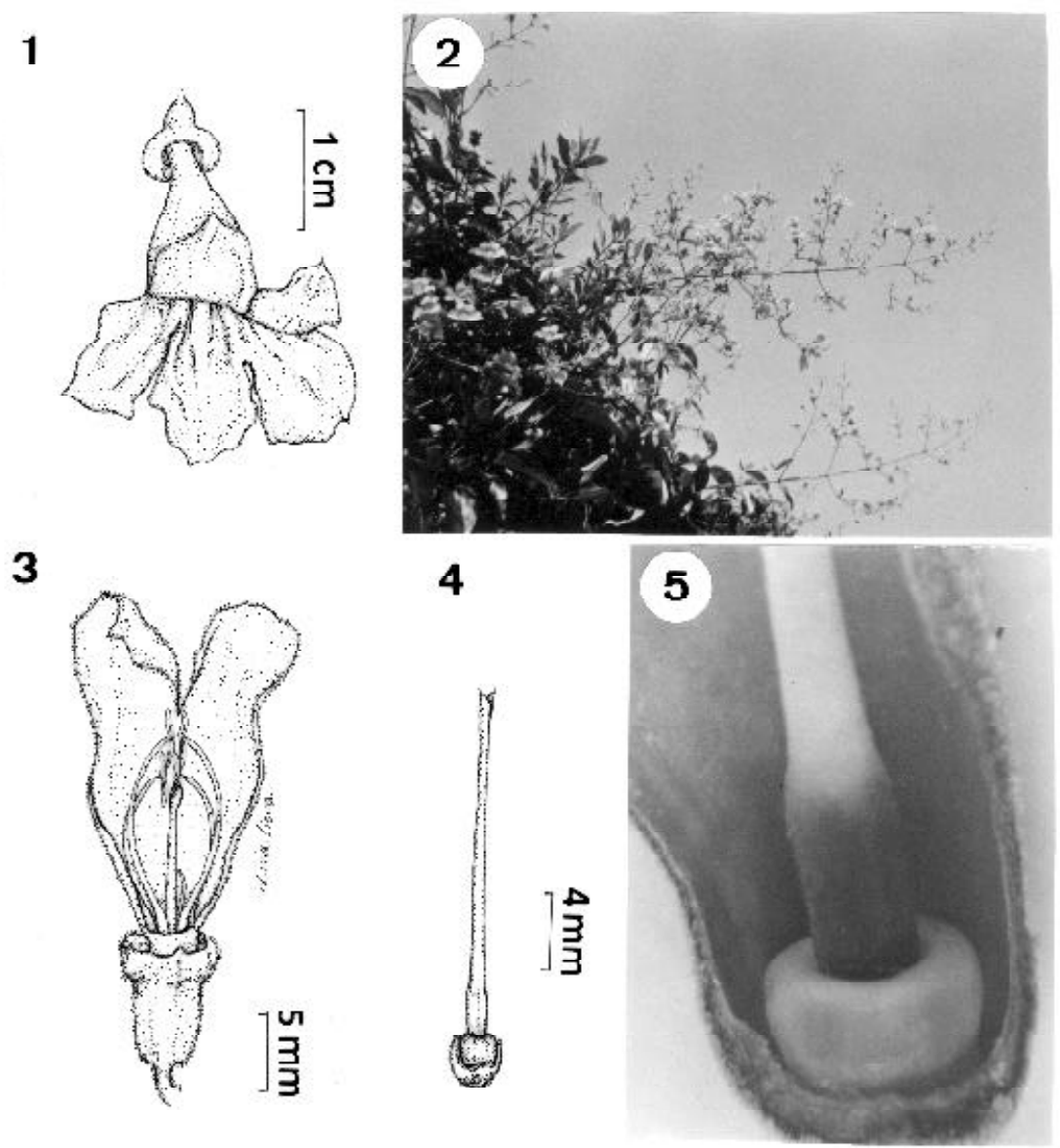

Figuras 1-5. 1. Flor de Arrabidaea conjugata (Vell.) Mart. 2. Inflorescências destacadas da folhagem x0,2. 3. Corte longitudinal da flor, mostrando disposição dos órgãos reprodutivos e o estaminódio. 4. Gineceu mostrando o disco nectarífero, ovário, estilete e estigma bífido. 5 . Detalhe do disco e da câmara nectarífera x10. 
A abertura dos botões inicia-se por volta das 7 h 30 min, com a distensão dos lacínios, que se afastam ficando dois voltados para cima e três para baixo. Por volta das $8 \mathrm{~h}$, os lacínios estão totalmente distendidos e o guia de néctar é bem aparente, iniciando-se a emissão de odor suave e adocicado. Entre $8 \mathrm{~h} 30 \mathrm{~min}$ e $9 \mathrm{~h}$, as flores entram em antese, ocorrendo simultâneamente a abertura dos lobos estigmáticos e a deiscência das anteras. Por volta das 9 h 30 min, o odor emitido é mais forte e todas as flores têm seus estigmas úmidos e receptivos. As flores têm duração de um dia e a queda da corola, que ocorre assincronicamente entre $15 \mathrm{~h} 30 \mathrm{~min}$ e $18 \mathrm{~h}$, caracteriza o fim da atividade floral.

Arrabidaea conjugata, na restinga de Maricá, floresce nos meses de dezembro a março, período mais correspondente à estação mais quente-chuvosa, com pico no mês de janeiro. A floração é do tipo cornucópia, sincrônica entre as áreas observadas e regular nos quatro anos estudados (Fig. 6). O crescimento vegetativo é contínuo, com aumento destacado no período de desenvolvimento de botões e na floração.

$\mathrm{O}$ fruto é uma cápsula linear achatada com média de $24,54 \mathrm{~cm}$ compr. $(\mathrm{N}=50$; desvio padrão $=2,94$ ). Apresenta coloração verde durante todo o desenvolvimento, tornando-se castanho próximo à liberação das sementes (Fig. 7a, b). O cálice é persistente e confere proteção aos frutos jovens, permanecendo lilás por cerca de 20 dias, passando então a castanho. As sementes são aladas, castanhas e liberadas gradativamente na estação mais fria-seca.

Nectários extraflorais estão distribuídos irregularmente por toda superfície dos frutos. Estes nectários já se encontram presentes na parede externa do ovário das flores, só que imaturos (inativos). Entretanto, entram em atividade, paulatinamente, com exsudações seqüenciais, durante todo o período de desenvolvimento dos frutos, cessando suas atividades por ocasião da liberação das sementes (Fig. 8). Essas glândulas nectaríferas são visitadas freqüentemente pelas mesmas formigas que visitam os nectários extraflorais do cálice.

Reprodução - Os experimentos de polinização indicam que a espécie é auto-incompatível e xenogâmica obrigatória (Tab. 1). Em A. conjugata registra-se aborto de frutos jovens, tanto em polinizações naturais (controle), como em polinizações cruzadas manualmente, num período de 45 dias após a polinização. Cerca de $75 \%$ das flores cruzadas manualmente iniciam o desenvolvimento de frutos, entretanto somente $12 \%$

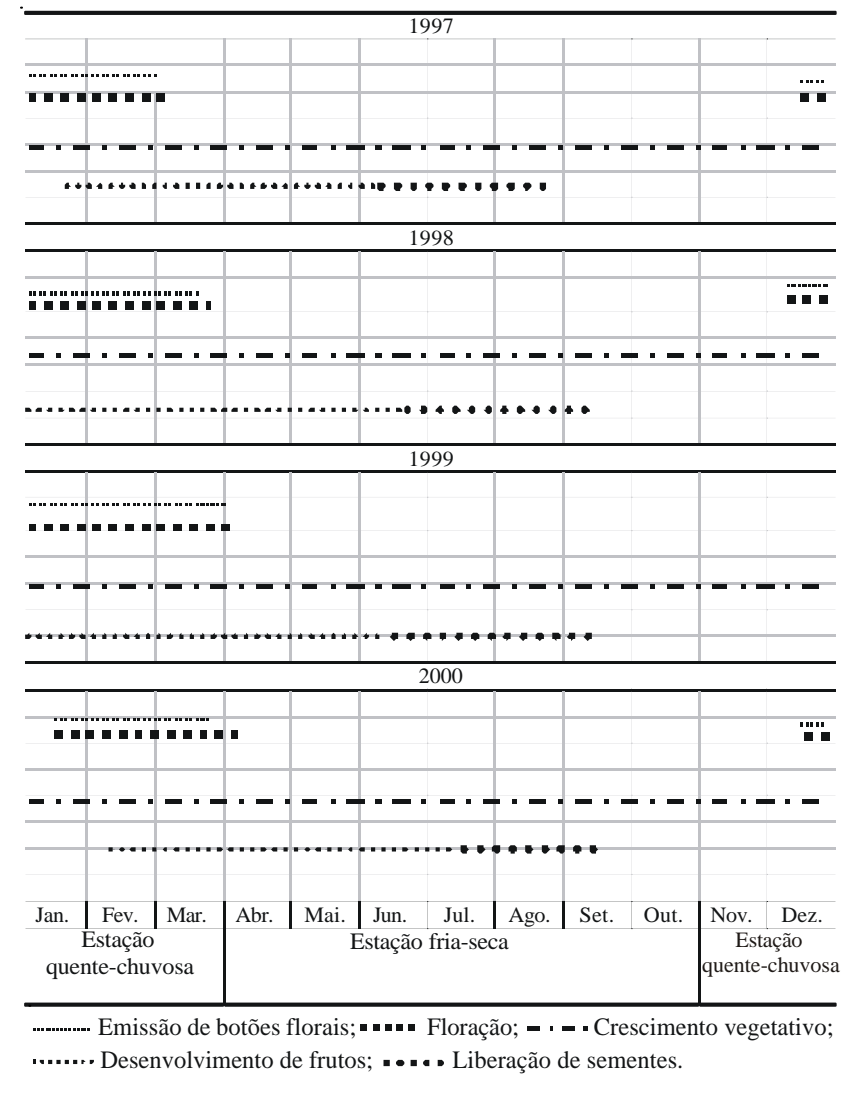

Figura 6. Eventos fenológicos de Arrabidaea conjugata (Vell.) Mart. observados em cinco áreas nas restingas do Município de Maricá, RJ, Brasil, ao longo de quatro anos.

dos frutos iniciados atingem a maturidade. O tempo de maturação dos frutos varia de três a sete meses e observa-se que nos frutos deiscentes prematuramente há grande número de sementes abortadas, ao passo que naqueles cujo desenvolvimento aproxima-se dos sete meses, o número de sementes viáveis é maior e o de sementes abortadas é menor (Fig. 9).

Polinizadores e pilhadores de néctar (Tab. 2) - As flores de A. conjugata são polinizadas pelas abelhas Euglossa cordata Linnaeus (Fig. 10a, b), Centris analis Fabricius e Centris tarsata Smith. As abelhas sobrevoam as flores e pousam sobre os lacínios, indo em direção à parte basal da corola para coletarem o néctar. Neste percurso, tocam, com a porção dorsal do tórax, nos lobos estigmáticos que se fecham em seguida. Neste momento ocorre a polinização. Após a coleta do néctar, as abelhas retrocedem pelo tubo floral até alcançarem os lacínios, de onde alçam vôo. Ao retrocederem, as abelhas pressionam as anteras e uma nova carga polínica é depositada na porção dorsal do tórax das mesmas. As visitas iniciam-se por volta das $8 \mathrm{~h}$, estendendo-se por todo o dia. Outros visitantes florais perfuram externamente o tubo da corola, 


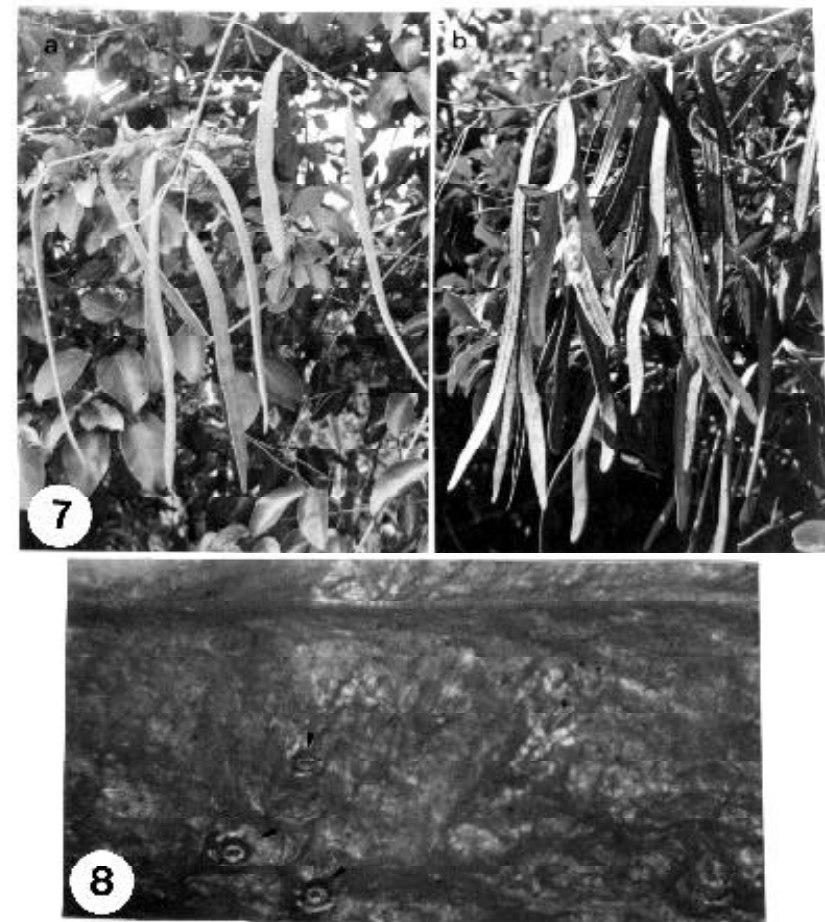

Figuras 7-8. 7. Frutos de Arrabidaea conjugata (Vell.) Mart. x0,3. a. Frutos em desenvolvimento; b. Frutos em deiscência. 8. Detalhe da superfície do fruto, mostrando os nectários extraflorais $\mathrm{x} 1,5$.

pilhando o néctar, entre eles Xylocopa ordinaria Smith (Fig. 11), X. frontalis Olivier, Eulaema nigrita Lepeletier, todos considerados pilhadores primários. As borboletas Urbanus proteus proteus Linnaeus (Fig. 12), Saliana matthiolus Herrich-Schaffer, Hylephila phyleus phyleus Drury e o beija-flor Eupetomena macroura Gmelin atuam como pilhadores secundários, pois aproveitam-se das perfurações feitas pelos pilhadores primários.

Dentre os pilhadores de néctar, destaca-se $X$. ordinaria. As visitas de pilhagem desta abelha iniciam-se por volta das $7 \mathrm{~h}$, quando os botões em préantese já apresentam néctar, mas ainda não completaram o processo de abertura. Estendem-se por

Tabela 1. Resultados dos experimentos sobre sistema de reprodução de Arrabidaea conjugata (Vell.) Mart. nas restingas do Município de Maricá, RJ, Brasil.

\begin{tabular}{lrcc}
\hline Experimentos & $\begin{array}{c}\text { Flores } \\
(\mathrm{n})\end{array}$ & $\begin{array}{c}\text { Frutos } \\
(\mathrm{n})\end{array}$ & $\begin{array}{c}\text { Sucesso } \\
(\%)\end{array}$ \\
\hline Autopolinização manual & 25 & 0 & 0 \\
Polinização cruzada (xenogamia) & 50 & 19 & 38,00 \\
Polinização natural (controle) & 155 & 19 & 12,25 \\
\hline
\end{tabular}

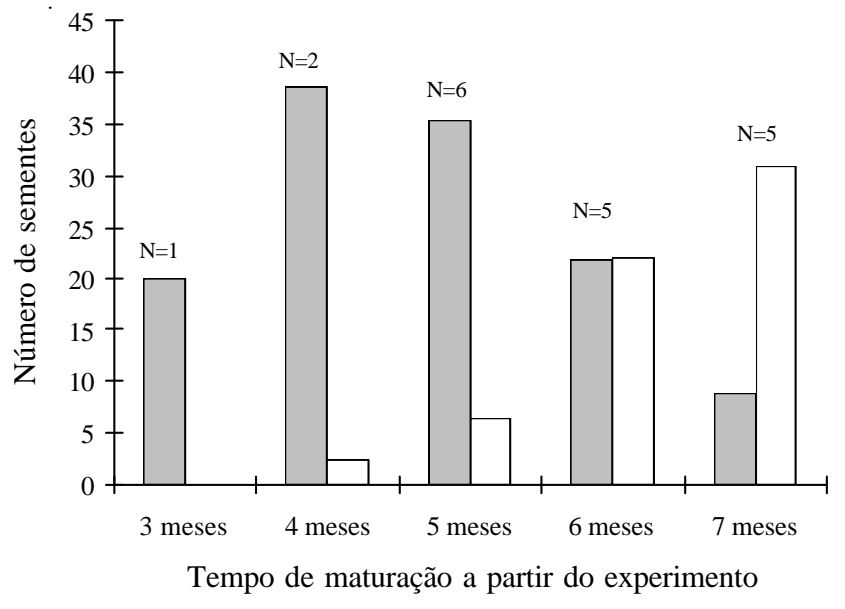

Figura 9. Distribuição do número de sementes abortadas e viáveis de frutos resultantes de polinizações cruzadas manuais de Arrabidaea conjugata (Vell.) Mart. de acordo com o tempo de maturação dos frutos, nas restingas do Município de Maricá, RJ, Brasil. $\square=$ sementes abortadas; $\square=$ sementes viáveis

Tabela 2. Atividade e frequiência relativa dos polinizadores e pilhadores de néctar em Arrabidaea conjugata (Vell.) Mart. nas restingas do Município de Maricá, RJ, Brasil. *Família Apidae, **Família Hesperiidae. Freqüência relativa dos visitantes: (1) pouco freqüente $(<50 \%)$; (2) freqüente $(\geq 50 \%$ e $<100 \%)$; (3) muito freqüente $(100 \%)$.

\begin{tabular}{ccc}
\hline Espécie & $\begin{array}{c}\text { Tamanho } \\
\text { aproximado } \\
(\mathrm{cm})\end{array}$ & \\
\hline
\end{tabular}

Abelhas

$\begin{array}{llcl}\text { Euglossa cordata* } & 1,0 & \text { Polinizador } & (3) \\ \text { Eulaema nigrita* } & 2,0 & \text { Pilhador de néctar } & (2) \\ \text { Centris analis }^{*} & 1,0 & \text { Polinizador } & (3) \\ \text { Centris tarsata }^{*} & 1,0 & \text { Polinizador } & (3) \\ \text { Xylocopafrontalis } & 2,5 & \text { Pilhador de néctar } & (1) \\ \text { Xylocopaordinaria* } & 2,8 & \text { Pilhador de néctar }\end{array}$

Borboletas

\begin{tabular}{lccc}
$\begin{array}{c}\text { Hylephila phyleus } \\
\text { phyleus }\end{array}$ & 2,0 & Pilhador de néctar & (2) \\
$\begin{array}{c}\text { Urbanus proteus } \\
\text { proteus }\end{array}$ & 5,0 & Pilhador de néctar \\
$\begin{array}{c}\text { Saliana matthiolus } \\
\text { ** }\end{array}$ & 3,5 & Pilhador de néctar \\
$\begin{array}{l}\text { Beija-flor } \\
\text { Eupetomena macroura }\end{array}$ & 18,0 & Pilhador de néctar \\
\hline
\end{tabular}

todo o dia, com pico entre 12 h e 15 h, quando num só vôo, são pilhadas até 240 flores. As borboletas U. proteus proteus, H. phyleus phyleus, S. matthiolus, e o beija-flor E. macroura iniciam suas visitas, junto com os polinizadores, por volta das $8 \mathrm{~h}$.

Polinizadores e pilhadores de néctar realizam visitas conjuntas, sem ocorrer qualquer manifestação 

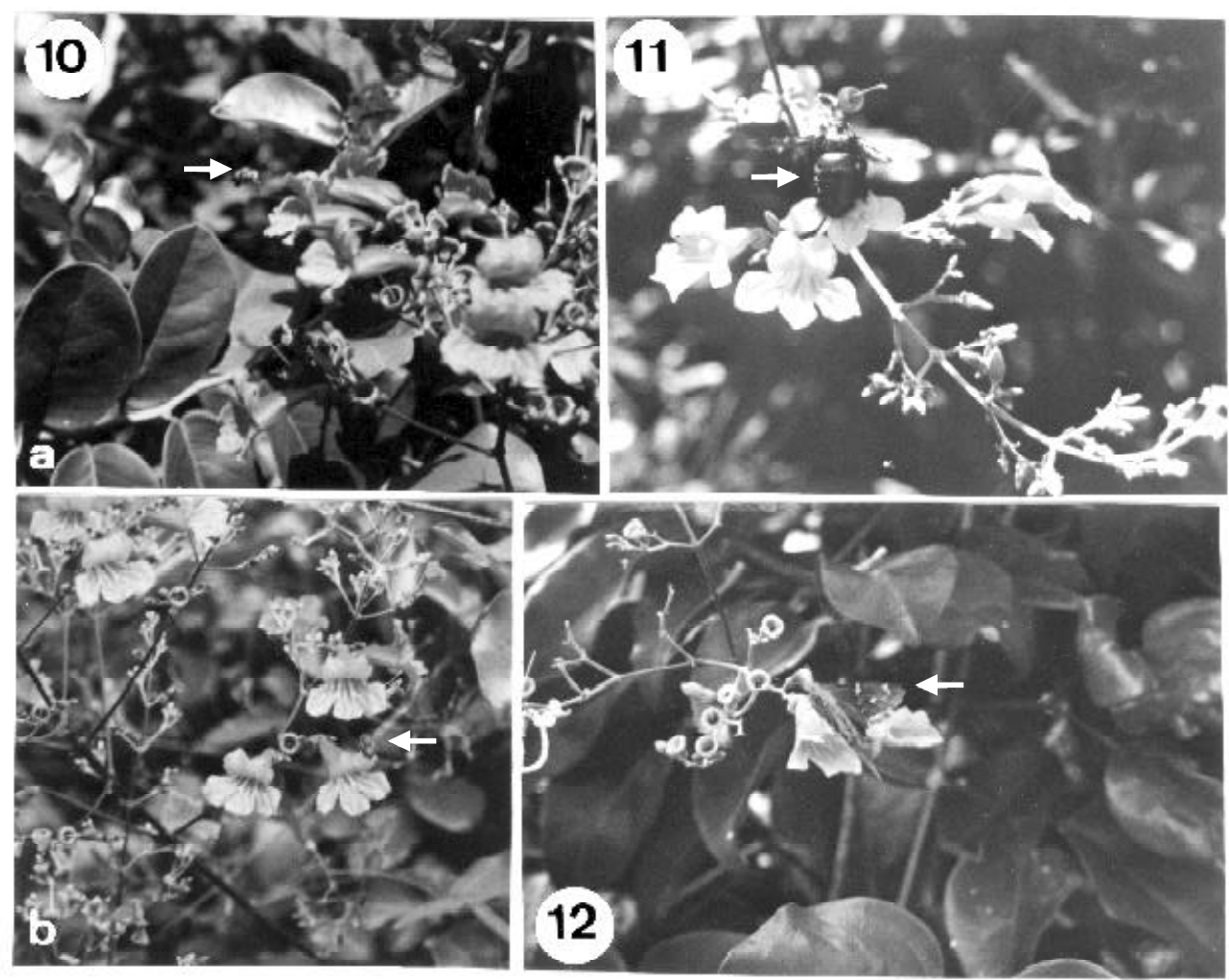

Figuras 10-12. Visita de polinizadores e pilhadores de nectar às flores de Arrabidaea conjugata (Vell.) Mart. 10. Visita de Euglossa cordata $\mathrm{x} 0,5$. a. Chegada da abelha; $\mathrm{b}$. Saída da abelha. 11. Pilhagem primária de Xylocopa ordinaria Smith x0,7. 12. Pilhagem secundária de Urbanus proteus proteus Linnaeus $\mathrm{x} 0,6$.

de comportamento agressivo entre eles. Os polinizadores visitam poucas flores por planta em comparação com os pilhadores (Fig. 13). As visitas dos polinizadores e dos principais pilhadores de néctar

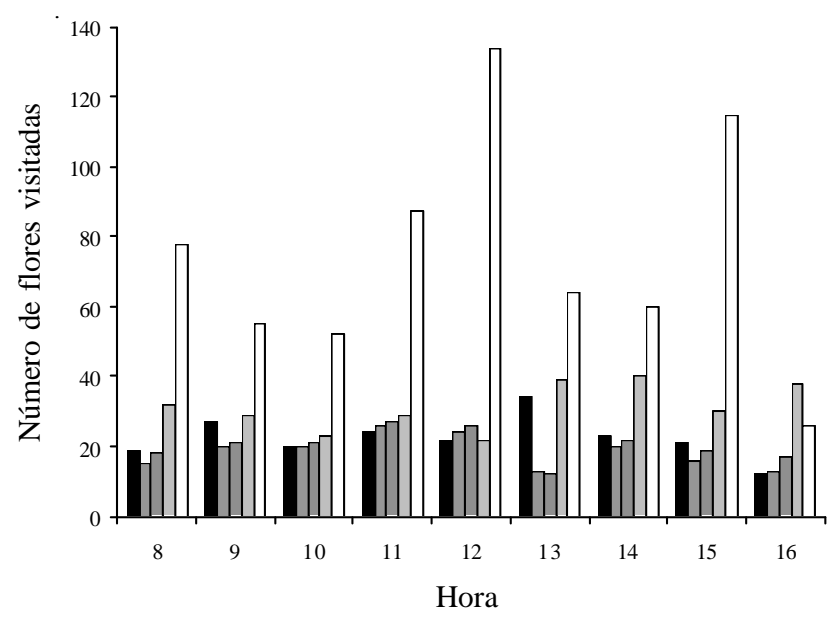

Figura 13. Distribuição do número de flores de Arrabidaea conjugata (Vell.) Mart. visitadas por polinizadores e principais pilhadores de néctar, ao longo de um dia, no pico de floração, nas restingas do Município de Maricá, RJ, Brasil. - = Euglossa

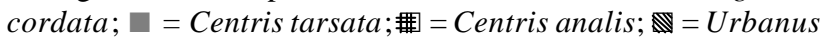
proteus proteus $; \square=$ Xylocopa ordinaria . às flores de $A$. conjugata estendem-se pelos períodos da manhã e da tarde, embora tenha sido registrado maior frequiência de visitas dos pilhadores no período da tarde (Fig. 14).

\section{Discussão}

A corola tubulosa e achatada dorso-ventralmente das flores de A. conjugata faculta o acesso ao néctar, de forma legítima, apenas para abelhas de médio porte. Abelhas de grande porte como Xylocopa, não conseguem penetrar no tubo da corola o suficiente para alcançar o néctar e, portanto, estão excluídas das visitas legítimas. No entanto, a consistência da corola não impede a pilhagem de néctar através da perfuração da base do tubo, por estas abelhas. A disposição dos órgãos reprodutivos nas flores de A. conjugata favorece a polinização cruzada uma vez que, no trajeto em direção ao néctar, as abelhas polinizadoras passam, necessariamente e nesta ordem, pelas áreas de recepção e de doação de pólen. Ressalta-se que o fechamento dos lobos estigmáticos contribui para reduzir a interferência destas funções (Stephenson \& Thomas 


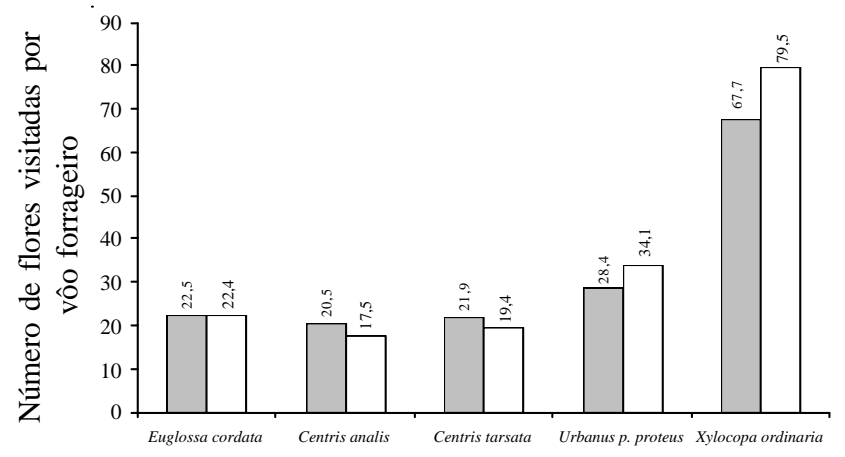

Figura 14. Distribuição do número médio de visitas, nos períodos da manhã e da tarde, dos polinizadores efetivos e principais pilhadores de néctar das flores de Arrabidaea conjugata (Vell.) Mart., nas restingas do Município de Maricá, RJ, Brasil. $=$ Manhã; $\square=$ Tarde.

1977; Stephenson 1979). A grande produção diária de flores e a disposição das inflorescências por toda a planta certamente são responsáveis pela atração à longa distância, o que pode ser atestado pela alta taxa de visitação, incluindo polinizadores e pilhadores. Estas características representam uma unidade de atração para os visitantes, o que está de acordo com Wyatt (1981); Brody \& Mitchell (1997) e Goulson et al. (1998), quando relatam que o arranjo das flores influencia o padrão de forrageio dos polinizadores.

Em A. conjugata os grãos de pólen não são expostos e a liberação dos mesmos está intimamente relacionada com as visitas dos polinizadores, que exercem pressões sobre as anteras eliminando grumos de pólen. Fato semelhante ocorre em Arrabidaea brachypoda (DC.) Bor., A. samydoides (Cham.) Sandw. e A. triplinervia H. Baill. (Yanagizawa, Y., 1983 - comunicação pessoal). A liberação gradativa de grãos de pólen a cada visita prolonga a fase de doação de pólen (Lloyd \& Yates 1982), de modo que visitas próximos ao final da antese podem ainda redundar em polinizações.

O néctar, único recurso oferecido aos visitantes florais, começa a ser secretado nos botões em préantese e está presente por toda a vida das flores, característica já observada em outras Bignoniaceae (Elias \& Gelband 1975; Bertin 1982; Gobatto Rodrigues \& Stort 1992; Galetto et al. 1994). Na espécie em estudo o néctar não é exposto, sendo, por esta razão, considerado de difícil acesso. Segundo Ormond et al. (1993) cerca de 70\% das espécies nectaríferas estudadas na restinga de Maricá apresentam néctar não exposto o que constitui condição vantajosa nesse ambiente sujeito a condições adversas que favorecem a evaporação e/ou mudanças na concentração do néctar.
Euglossa cordata, Centris analis e C. tarsata são os polinizadores da espécie estudada. Gentry (1974a) assinala que fêmeas de Euglossini são os mais eficientes polinizadores em espécies melitófilas de Bignoniaceae do Panamá e da Costa Rica. Espécies de Euglossa são também consideradas polinizadores efetivos de outras espécies desta família (Barrows 1977; Gentry 1979a). O fato dessas abelhas terem glossa longa favorece a coleta de néctar das flores tubulares (Pinheiro \& Schlindwein 1998). Espécies de Centris são apontadas como principais polinizadores de Tabebuia da Costa Rica por Frankie et al. (1983). Silberbauer-Gottsberger \& Gottsberger (1988) consideram espécies de Centris, Bombus e Xylocopa como principais polinizadores das bignoniáceas do cerrado.

Xylocopa ordinaria é o principal pilhador primário, chegando a perfurar todas as flores produzidas no dia. A atividade de pilhagem de néctar, por espécies de Xylocopa, é muito documentada na família Bignoniaceae (Gentry 1974a; 1974b; Laroca \& Almeida 1985; Vieira et al. 1992; Gobatto-Rodrigues \& Stort 1992; Galetto 1995). Em A. conjugata registra-se, simultaneamente uma atividade de pilhagem secundária por três espécies de borboletas $\mathrm{e}$ de um beija-flor. Desta forma, a intensa e contínua pilhagem das flores diminui a disponibilidade de néctar para os polinizadores, possivelmente obrigando-os a aumentarem a área de forrageio. Tal fato poderia promover um maior número de visitas entre as plantas, aumentando, consequentemente, o fluxo de pólen entre as mesmas e favorecendo polinizações cruzadas (Roubik 1982; Roubik etal. 1985; Gill 1988). Camargo et al. (1984), Vieira et al. (1992) e Barros (2001), destacam que os pilhadores de néctar têm uma participação efetiva na ecologia da polinização das espécies de Bignoniaceae, o que está de acordo com os resultados que mostram que o número de visitas dos pilhadores, especialmente de Xylocopa ordinaria, representa cerca do dobro ou mais do número de visitas dos polinizadores.

Os experimentos de autopolinização manual em A. conjugata revelaram a presença de autoincompatibilidade, já registrada para outras espécies de Bignoniaceae (Bawa 1974; Stephenson \& Thomas 1977; Stephenson 1979; Bertin 1982; Bertin \& Sullivan 1988; Vieira et al. 1992; Sampaio \& Almeida 1995).

Arrabidaeae conjugata caracteriza-se por uma baixa produtividade de frutos (Frutos/Flores $=12,5 \%$ ). De acordo com Sutherland \& Delph (1984), as plantas 
hermafroditas produzem excesso de flores que não redundam em frutos, expresso pela proporção Frutos/ Flores média de $42,1 \%$, sendo ainda mais baixas para as espécies auto-incompatíveis $(22,1 \%)$. Os baixos valores obtidos para A. conjugata também ocorrem em outras Bignoniaceae (Vieira et al. 1992; GobattoRodrigues \& Stort 1992; Gibbs \& Bianchi 1999). Muitas hipóteses têm sido levantadas para explicar esse modelo de baixa produção de frutos, destacando-se entre elas a limitação de pólen ou de polinizadores e a limitação de nutrientes maternos - aborto seletivo (Stephenson 1981; Bawa \& Webb 1984; Sutherland 1987; Charlesworth 1989). Na espécie em estudo, parece não haver limitação da quantidade de pólen e de polinizadores, uma vez que ocorre intensa visitação às flores. Além do mais, a liberação gradativa dos grãos de pólen permite que os mesmos fiquem disponíveis ao longo da antese. Estudos realizados em Tabebuia aurea (Manso) Benth. \& Hook. e T. ochracea (Cham.) Standl. mostram que a baixa produção de frutos nas polinizações naturais e polinizações cruzadas manuais não está relacionada à ausência de polinizadores, já que as espécies também são intensamente visitadas (Barros 2001). O fato dos experimentos de xenogamia em $A$. conjugata terem resultado em um maior número de frutos do que nas polinizações naturais (controle), não prova que a produção de frutos seja limitada apenas pela polinização, já que flores polinizadas manualmente têm em geral, uma maior probabilidade de iniciar e desenvolver frutos do que aquelas polinizadas naturalmente (Stephenson 1981). Por outro lado, em A. conjugata registra-se aborto de frutos jovens, num período de um mês após a polinização, tanto em polinizações naturais (controle) como em polinizações xenogâmicas manuais. Gentry (1974a) considera que $\mathrm{o}$ aborto de frutos ainda pequenos, em Bignoniaceae, seria uma carência nutricional, já que a planta não tem possibilidade de manter toda a produção de frutos. Quando o sucesso da polinização é alto e muitos frutos são iniciados, a planta pode seletivamente abortar alguns frutos e madurar somente aqueles de melhor qualidade, seja em termos de número de óvulos fertilizados ou da constituição genética das sementes, adaptando, assim, o número de frutos em desenvolvimento à disponibilidade dos recursos maternos (Stephenson 1981; Bawa \& Webb 1984; Sutherland \& Delph 1984). Assim, o aborto de frutos observados na espécie aqui estudada pode ser uma resposta adaptativa, como o aborto seletivo de frutos proposto pelos autores acima referidos.

\section{Agradecimentos}

Ao Prof. Dr. Sebastião Laroca, da Universidade Federal do Paraná (UFPR), pela determinação das abelhas; ao Prof. Antônio José Mayhé Nunes, da Universidade Federal Rural do Rio de Janeiro, pela identificação das formigas; ao biólogo Alexandre Soares, do Departamento de Entomologia do Museu Nacional/UFRJ, pela identificação das borboletas.

\section{Referências bibliográficas}

Alexander, M.P. 1980. A versatile stain for pollen, fungi yeast and bacteria. Stain Technology 55(1): 13-18.

Araújo, D.S.D. \& Henriques, R.P.B. 1984. Análise florística das restingas do Rio de Janeiro. Pp. 159-194. In: L.D. Lacerda; D.S.D. Araújo; R. Cerqueira \& B. Turcq (orgs.). Restingas, origem, estrutura, processos. Niterói, Universidade Federal Fluminense (CEUFF).

Barros, M.G. 2001. Pollination ecology of Tabebuia aurea (Manso) Benth. \& Hook. and T. ochracea (Cham.) Standl. (Bignoniaceae) in Central Brazil cerrado vegetation. Revista Brasileira de Botânica 24(3): 255-261.

Barrows, E.M. 1977. Floral maturation and insect visitors of Pachyptera hymenaea (Bignoniaceae). Biotropica 99(2): 133-134.

Bawa, K.S. 1974. Breeding systems of tree species of a lowland tropical community. Evolution 28: 85-92.

Bawa, K.S. \& Webb, C.J. 1984. Flower, fruit and seed abortion in tropical forest trees: implications for the evolution of paternal and maternal reproductive patterns. American Journal of Botany 71(5): 737-751.

Bertin, R.I. 1982. Floral biology, hummingbird pollination and fruit production of trumpet creeper (Campsis radicans, Bignoniaceae). American Journal of Botany 69(1): 122-134.

Bertin, R.I. \& Sullivan, M. 1988. Pollen interference and cryptic self-fertility in Campsis radicans. American Journal of Botany 75(8): 1140-1147.

Bittencourt Jr., N.S.; Gibbs, P.E. \& Semir, J. 2003. Histological study of post-pollination events in Spathodea campanulata Beauv. (Bignoniaceae), a species with lateacting self-incompatibility. Annals of Botany 91(4): 827-834.

Brody, A.K. \& Mitchell, R.J. 1997. Effects of experimental manipulation of inflorescence size on pollination and pre-dispersal seed predation in the hummingbirdpollinated plant Ipomopsis aggregata. Oecologia 110: 86-93.

Camargo, J.M.F.; Gottsberger, G. \& Silberbauer-Gottsberger, I. 1984. On the phenology and flower visiting behavior of Oxaea flavences (Klug) (Oxaeinae, Andrenidae, Hymenoptera) in São Paulo, Brasil. Beiträge zur Biologie der Pflanzen 59: 159-179. 
Charlesworth, D. 1989. Evolution of low female fertility in plants: pollen limitation, resource allocation and genetic load. Tree 4(10): 289-292.

Elias, T.S. \& Gelband, H. 1975. Nectar: Its production and functions in trumpet creeper. Science 189: 289-291.

Elias, T.S. 1983. Extrafloral nectaries: their structure and distribution. Pp. 174-203. In: B. Bentley \& T. Elias (eds.). The Biology of nectaries. New York, Columbia University Press.

Elias, T.S. \& Gelband, H. 1976. Morphology and anatomy of floral and extrafloral nectaries in Campsis (Bignoniaceae). American Journal of Botany 63(10): 1349-1353.

Elias, T.S. \& Prance, G.T. 1978. Nectaries on the fruit of Crescentia and other Bignoniaceae. Brittonia 30(2): $175-181$.

Frankie, G.W.; Haber, W.A.; Opler, P.A. \& Bawa, K.S. 1983. Characteristics and organization of the large bee pollination system in the Costa Rican dry forest. Pp. 411-447. In: C.E. Jones \& R.J. Little (eds.). Handbook of experimental pollination biology. New York, Scientific and Academic Editions.

Galetto, L. 1995. Nectary structure and nectar characteristics in some Bignoniaceae. Plant Systematics and Evolution 196: $99-121$.

Galetto, L.; Bernardello, L.M. \& Julliani, H.R. 1994. Characteristcs of secretion of nectar in Pyrostegia venusta (Ker-Gawl.) Miers (Bignoniaceae). New Phytologist 127(3): 465-472.

Gentry, A.H. 1974a. Flowering phenology and diversity in tropical Bignoniaceae. Biotropica 6(1): 64-68.

Gentry, A.H. 1974b. Coevolutionary patterns in Central American Bignoniaceae. Annals of the Missouri Botanical Garden 61: 728-759.

Gentry, A.H. 1976. Bignoniaceae of sourthern Central America: distribution and ecological specificity. Biotropica 8(2): 117-131.

Gentry, A.H. 1979a. Taxonomic implications of Bignoniaceae palynology. Annals of the Missouri Botanical Garden 66: 756-777.

Gentry, A.H. 1979b. Additional generic mergers in Bignoniaceae. Annals of the Missouri Botanical Garden 66: $778-787$.

Gentry, A.H. 1990. Evolutionary paterns in Neotropical Bignoniaceae. Memoirs of the New York Botanical Garden55: 118-129.

Gibbs, P.E. \& Bianchi, M. 1993. Post-pollination events in species of Chorisia (Bombacaceae) and Tabebuia (Bignoniaceae) with late-acting self-incompatibility. Botanica Acta 106: 64-71.

Gibbs, P.E. \& Bianchi, M. 1999. Does Late-acting selfincompatibility (LSI) show family Clustering? Two more species of Bignoniaceae with LSI: Dolichandra cynanchoides and Tabebuia nodosa Annals of Botany 84: 449-457.

Gill, F.B. 1988. Effects of nectar removal on nectar accumulation in flowers of Heliconia imbricata (Heliconiaceae). Biotropica 20: 169-171.
Gobatto-Rodrigues, A.A. \& Stort, M.N.S. 1992. Biologia floral e reprodução de Pyrostegia venusta (Ker-Gawl.) Miers (Bignoniaceae). Revista Brasileira de Botânica 15(1): 37-41.

Goulson, D.; Stout, J.C.; Hawson, S.A. \& Allen, J.A. 1998. Floral display size in comfrey, Symphytum officinale L. (Boraginaceae): relationships with visitation by three bumblee species and subsquent seed set. Oecologia 113: 502-508.

Heslop-Harrison, Y. \& Shivanna, K.R. 1977. The receptive surface of the Angiosperm stigma Annals of Botany 41(176): 1233-1258.

Inouye, D.W. 1983. The ecology of nectar robbing. Pp. 153-173 In: B. Bentley \& T. Elias (eds.). The biology of nectaries. New York, Columbia University Press.

Johansen, D.A. 1940. Plant microtechnique. New York, McGraw-Hill Book Company Inc.

Laroca, S. \& Almeida, M.C. 1985. A adaptação dos palpos labiais de Niltonia virgilii (Hymenoptera, Apoidea, Colletidae) para coleta de néctar em Jacaranda puberula (Bignoniaceae), com descrição do macho. Revista Brasileira de Entomologia 29(2): 289-297.

Lloyd, D.G. \& Yates, J.M.A. 1982. Intrasexual selection and the segregation of pollen and stigmas in hermaphodite plants, exemplified by Wahlenbergia albomarginata (Campanulaceae). Evolution 36: 903-913.

Ormond, W.T.; Pinheiro, M.C.B.; Lima, H.A.; Correia, M.C.R. \& Pimenta, M.L. 1993. Estudo das recompensas florais das plantas da restinga de Maricá, RJ. I - Nectaríferas. Bradea 6(21): 179-195.

Pereira, O.J. \& Araújo, D.S.D. 2000. Análise florística das restingas dos Estados do Espírito Santo e Rio de Janeiro. Pp. 25-63. In: F.A. Esteves \& L.D. Lacerda (eds.). Ecologia de Restingas e Lagoas Costeiras. Macaé, Núcleo de Pesquisa Ecológica de Macaé (NUPEM/UFRJ).

Pinheiro, M. \& Schlindwein, C. 1998. A câmara nectarífera de Ipomoea cairica (Convolvulaceae) e abelhas de glossa longa como polinizadores eficientes. Iheringia Série Botânica 51(1): 3-16.

Roubik, D.W. 1982. The ecological impact of nectar-robbing bees and pollination hummingbirds on a tropical shrub. Ecology 63(2): 354-360.

Roubik, D.W.; Holbrook, N.M. \& Parra, G. 1985. Roles of nectar robbes in reproduction of the tropical treelet Quassia amarra (Simaroubaceae). Oceologia 66: 161-167.

Sampaio, E.S. \& Almeida, A.A. 1995. Morfologia floral e biologia reprodutiva de Pyrostegia venusta (Bignoniaceae) na região urbana de Curitiba. Acta Biologica Paranaense 24(1-4): 25-38.

Schneider, E.P.M. \& Londero, I.W.B. 1965. Flora ilustrada do Rio Grande do Sul. Fascículo VI - Bignoniaceae. Boletim do Instituto de Ciências Naturais 25: 1-40.

Silberbauer-Gottsberger, I. \& Gottsberger, G. 1988. A polinização de plantas do cerrado. Revista Brasileira de Biologia 48: 651-663.

Stephenson, A.G. 1979. An evolutionary examination of the floral display of Catalpa speciosa (Bignoniaceae). Evolution 33: 1200-1209. 
Stephenson, A.G. 1981. Flower and fruit abortion: proximate causes and ultimate functions. Annual Review of Ecology Systematics 12: 253-279.

Stephenson, A.G. \& Thomas, W.W. 1977. Diurnal and nocturnal pollination of Catalpa speciosa (Bignoniaceae). Systematic Botany 2(3): 191-198.

Sutherland, S. 1987. Why hermaphroditic plants produce many more flowers than fruits: experimental testes with Agave mckelveyana. Evolution 4(4): 750-759.

Sutherland, S. \& Delph, L.F. 1984. On the importance of male fitness in plants; patterns of fruit-set. Ecology 65(4): 1093-1104.
Vieira, M.F.; Meira, M.R.S.A.; Queiroz, L.P. \& Neto, J.A.A.M. 1992. Polinização e reprodução de Jacaranda caroba (Vell.) DC. Bignoniaceae, em área de cerrado do sudeste do Brasil. Pp. 13-19. In: Anais do $8^{\circ}$ Congresso da Sociedade Botânica de São Paulo.

Whitham, T.G. 1977. Coevolution of foraging in Bombus and nectar dispensing in Chilopsis: A last dreg theory. Science 197: 593-596.

Wyatt, R. 1981. Ant-pollination of the granite out crop endermic Diamorpha smallii (Crassulaceae). American Journal of Botany 68: 1212-1217. 